\title{
Estimating flooded area and mean water level using active and passive microwaves: the example of Paraná River Delta floodplain
}

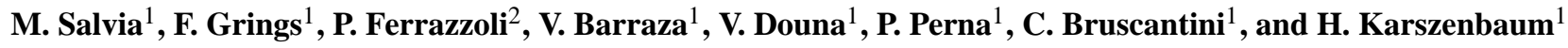 \\ ${ }^{1}$ Instituto de Astronomía y Física del Espacio (IAFE, CONICET-UBA), Ciudad Universitaria, Pabellón IAFE, \\ Buenos Aires, Argentina \\ ${ }^{2}$ Tor Vergata University, Ingegneria, DISP, 00133 Rome, Italy
}

Received: 27 December 2010 - Published in Hydrol. Earth Syst. Sci. Discuss.: 21 March 2011

Revised: 12 July 2011 - Accepted: 8 August 2011 - Published: 26 August 2011

\begin{abstract}
This paper describes a procedure to estimate both the fraction of flooded area and the mean water level in vegetated river floodplains by using a synergy of active and passive microwave signatures. In particular, $\mathrm{C}$ band Envisat ASAR in Wide Swath mode and AMSR-E at $\mathrm{X}, \mathrm{Ku}$ and $\mathrm{Ka}$ band, are used. The method, which is an extension of previously developed algorithms based on passive data, exploits also model simulations of vegetation emissivity. The procedure is applied to a long flood event which occurred in the Paraná River Delta from December 2009 to April 2010. Obtained results are consistent with in situ measurements of river water level.
\end{abstract}

\section{Introduction}

Over the past decade, several flood monitoring/forecasting methodologies, based on remote sensing data, have been proposed. Among them, the ones based on microwave observations are the most successful, since large flood events and intense cloud covers are often encountered simultaneously. Furthermore, since flood events are dynamic processes, high temporal and spatial resolutions are usually required. However, due to orbital and technical constraints, both requirements are generally not achievable.

In this context, several microwave based flood monitoring techniques were developed. Among them, it is worth mentioning direct measuring techniques based on scatterometer data (Prigent et al., 2007), interferometric techniques (Alsdorf et al., 2007) and the fusion of remote sensing-derived

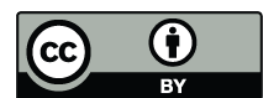

Correspondence to: F. Grings

(verderis@iafe.uba.ar) flood boundaries with topographic data (Pappenberger et al., 2007; Matgen et al., 2007; Zwenzner and Voigt, 2009, all based on SAR data) and the estimation of flooded areas with passive microwave signatures (Sippel et al., 1994).

Active microwave techniques, particularly interferometric ones, can provide accurate results. However, the relatively low temporal resolution and the small spatial extent limit their applicability. In general, these techniques are constrained to small areas and low temporal resolutions. Furthermore, active microwave methods have further limitations (e.g. interferometry needs suitable interferometric pairs, and fusion techniques require accurate DEMs of the area). On the other hand, passive microwave techniques, characterized by low spatial resolution and high temporal resolution, can provide rough estimates of flooded fraction in certain floodplain regions with virtually no ancillary data (Sippel et al., 1994). Therefore, passive microwaves are often exploited. This is particularly true in large river basins, where extreme flood events compromise thousands of square kilometers in a few days.

From a physical point of view, the sensitivity of microwave measurements to soil and vegetation properties was proved by several theoretical and experimental investigations (Ulaby et al., 1986). In many cases, passive microwave investigations adopt the absolute difference between the vertically and horizontally polarized brightness temperatures $\Delta T=\left(T_{\mathrm{bv}}-T_{\mathrm{bh}}\right)$ (Choudhury, 1989) as a useful index to monitor soil and vegetation conditions. In other cases, the same difference is normalized to the average value (Polarization Index, PI $\left.=2 * \Delta T /\left(T_{\mathrm{bv}}+T_{\mathrm{bh}}\right)\right)$ (Paloscia et al., 1993) with the advantage to reduce, or eliminate, the dependence on surface temperature. For angles higher than $30^{\circ}-40^{\circ}$, it was proved that both $\Delta T$ and PI are high for wet, flat and bare soils, while their values are reduced if the soil is dry,

Published by Copernicus Publications on behalf of the European Geosciences Union. 
and in presence of roughness and/or vegetation cover (Ulaby et al., 1986; Choudhury, 1989; Kerr and Njoku, 1990; Paloscia et al., 1993; Jackson and Schmugge, 1991; Paloscia and Pampaloni, 1988; Ferrazzoli et al., 1992). All the effects produced by flooding contribute to an increase of $\Delta T$ and PI.

In particular, flooding increases the moisture of the surface and decreases its roughness. For higher water levels, and in presence of vegetation cover, flooding also reduces the height of the emerged vegetation. In extreme cases, water level submerges vegetation. Therefore, the polarization indexes have the potential to detect the fraction of inundated area and to monitor the increase of water level. Finally, it is important to mention that these effects are present at all microwave frequencies. Lower frequencies show a better dynamics, but are characterized by worse spatial resolution.

Also the influence of surface variables on radar signatures was investigated extensively for various environments, such as crops, forests, natural low vegetation, and urban areas. For the active microwave case in natural areas, the overall backscattering coefficient is essentially influenced by three processes: surface direct contribution, vegetation contribution and surface-vegetation double bounce. At lower frequencies ( $\mathrm{L}, \mathrm{C}$ and $\mathrm{X}$ band) and angles higher than about $30^{\circ}$, the three contributions behave and interact in a complex way. Surface backscattering increases with moisture and roughness. Vegetation attenuates surface backscattering and produces its own contribution, as well as double bounce. Flooding reduces the surface contribution, due to the decrease of roughness, and increases the double bounce effect in vegetated areas. At $\mathrm{C}$ band, the overall effect produced by a moderate flooding in vegetated areas is an increase of the backscattering coefficient due to an increase of the double bounce contribution. However, if the increase of water level submerges most of the vegetation cover, the overall effect is a decrease of backscattering coefficient. Therefore, the trend of the backscattering coefficient as a function of water level is not monotonic. These properties have been investigated for some cases of agricultural and natural vegetation, mostly at $\mathrm{C}$ and $\mathrm{X}$ band, also with the aid of models (Le Toan et al., 1989; Caizzone et al., 2009; Grings et al., 2005). In vegetated areas, the increase of the backscattering coefficient during flooding related to double bounce was detected also in forest areas, using L band signatures (Wang et al., 1995).

The above mentioned properties make microwave remote sensing a good candidate for flood monitoring of large river basins. Some algorithms were designed to integrate both active and passive information in order to estimate flood conditions. A global study about flood dynamics was carried out using SSM/I signatures in synergy with data collected by AVHRR and ERS scatterometer (Prigent et al., 2007). However, most of the operational algorithms still use only passive or active data. Several authors proposed methodologies to estimate flooded area as a function of brightness temperature (or derived indexes) and ancillary information. In Choudhury (1989) the sensitivity of the polarization differ- ence $(\Delta T)$ measured at Ka band to flood events was investigated. Nimbus 7 data was used to monitor the Amazon River, and a strong seasonal pattern partially correlated to river water level was found.

An operational algorithm based on passive microwave data which estimates the fraction of flooded area was developed by Sippel et al. (1994) and further developed in Sippel et al. (1998) and Hamilton et al. (2002). Using physical hypotheses about the emissivity of water and vegetation, this algorithm estimates the fraction of flooded area of a pixel as a function of the absolute polarization difference $(\Delta T)$ at a given frequency. The fractional flooded area is estimated using linear mixing models that account for the microwave emission of the major land covers within the subregion (Sippel et al., 1994). This algorithm was tested using Ka band of SSM/I system. It assumes that the temperature difference of flooded land, $\Delta T_{\mathrm{f}}$, has a constant value for all the flooded vegetation types present in the area. This assumption is critical, since $\Delta T_{\mathrm{f}}$ can present large variations as reported by Sippel et al. (1994, 1998) and Hamilton et al. (2002). In part, these variations are simply related to the statistical inhomogeneity of vegetation cover in the dimension of the spaceborne radiometer pixel, which is of the order of hundreds of $\mathrm{km}^{2}$. However, they are also physically related to variations of water level in vegetated areas, as previously observed in Sippel et al. (1998) and Hamilton et al. (2002). Moreover, this dependency on water level is related to vegetation structure; in fact, for wetland marshes an increase in water level corresponds to a proportional decrease in the emerged biomass, with severe effects on the vegetation emissivity. On the contrary, in arboreous vegetation an increase in water level is related to a decrease in trunk height, a component of the vegetation that has negligible emission properties for frequencies $\geqq 6.9 \mathrm{GHz}$.

The objective of this paper is to estimate both the fraction of inundated area and the mean water level inside a wetland. The Paraná River Delta is selected as test site. The work adopts techniques of previous papers, such as the formulas of Sippel et al. (1994) and an emission model (Ferrazzoli and Guerriero, 1996a) that is able to simulate the vegetation polarization difference as a function of water level. The general approach is based on the use of both active and passive signatures, collected almost simultaneously. First of all, the fraction of inundated area is evaluated by applying a threshold technique to Envisat ASAR signatures collected in the Wide Swath (WS) mode. Then, AMSR-E signatures are used and formulas of Sippel et al. (1994) are inverted, in order to estimate $\Delta T_{\mathrm{f}}$. Finally, the average water level is estimated by inverting the results of model simulations. In this procedure three AMSR-E channels, i.e. X, Ku and Ka band, are tested. $\mathrm{C}$ band is not considered, due to its poor spatial resolution. Some empirical corrections are used to remove the effects of the continental area. 
Section 2 gives details about the study area and the used satellite signatures. Moreover, it describes all the details of the adopted procedure. The obtained results are shown and commented in Sect. 3.

\section{Materials and methods}

\subsection{Description of the site and available maps}

The Paraná River Delta (PRD) region stretches through the final $300 \mathrm{~km}$ of the Paraná basin. It covers approximately $17500 \mathrm{~km}^{2}$, close to Buenos Aires city in Argentina. A land cover map is shown in Fig. 1, in which the locations of the five water level stations considered in this paper are indicated.

The Paraná River drains an approximate area of $2310000 \mathrm{~km}^{2}$ and, according to its length, basin size, and water discharge, is considered the second most important one in South America after the Amazonas. Among the large rivers of the world, it is the only one that flows from tropical to temperate latitudes, where it joins the Uruguay River ending in the Del Plata estuary.

The landscape patterns of this region are subordinated to a flooding regime characterized by different sources of water with different properties, such as local precipitation and large rivers, whose specific flooding patterns affect particular areas. Sometimes these sources add together provoking strong flooding events, with main peaks in late summer and in winter.

The combination of local topographic gradients and a regional flooding regime constitutes the primary factor that determines the emergent natural vegetation, mainly consisting of marshes growing in lowlands where the substrate is saturated permanently or semi permanently (Parmuchi et al., 2002). In the specific area of the Delta under study, there are four ecosystems that account for more than $95 \%$ of the landcover: junco marsh, cortadera marsh, grassland and prairie of aquatic herbaceous vegetation. All these ecosystems are composed by herbaceous vegetation, which presents an average height of $2 \mathrm{~m}$. Some of them (Cortadera marsh, grassland) are mainly composed by leafy vegetation with nearly uniform density and an average LAI of $\sim 5$. The other ones (junco marsh, praire) are composed by nearly vertical long stems, with an average density of $\sim 90$ plants $\mathrm{m}^{-2}$. The selected area is indicated as a rectangle in Fig. 1. It includes a significant fraction of the Delta. For operational reasons, which will be explained later, also a continental part is considered, but its contribution will be subtracted. Therefore, the part of the Delta where the fraction of flooded area and the mean water level as a function of time will be evaluated is dominated by two marsh species: Junco (Schoenoplectus californicus), and Cortadera (Scirpus giganteus) (Salvia et al., 2009).

\subsection{Available data}

To estimate the hydrological condition of this area, we used both active and passive microwave signatures, as well as ancillary data. In particular, we used Wide Swath Envisat ASAR data and brightness temperature AMSR-E data. Details about product characteristics are given in Table 1 .

Seven acquisition dates were available for ASAR data. They are, in Julian days starting from 1 January 2009: 161, $231,264,336,353,371$ and 476 . The first date, which corresponds to non flooded conditions, was selected as a reference. A change detection algorithm was applied to the subsequent six acquisitions. The corresponding six AMSR-E dates were selected in order to be as close as possible to ASAR ones, with the further condition to be separated by multiples of 16 days, which corresponds to the repeat orbit. Following these criteria, the selected AMSR-E Julian dates are: 232, 264, 328, 344, 376 and 472 .

AMSR-E is a microwave radiometer operating at six frequency bands: $6.925 \mathrm{GHz}(\mathrm{C}), 10.65 \mathrm{GHz}(\mathrm{X}), 18.7 \mathrm{GHz}$ $(\mathrm{Ku}), 23.8 \mathrm{GHz}, 36.5 \mathrm{GHz}(\mathrm{Ka})$, and $89.0 \mathrm{GHz}$ (Kawanishi et al., 2003) (Parkinson, 2003). A conical scanning is used to observe the terrestrial surface with a local angle of $55^{\circ}$. The Instantaneous Field of View (IFOV) is dependent on frequency. In order to compare among different bands, in this work we used products with the resolution of $\mathrm{X}$ band, i.e. AMSR-E Res-2, $29 \times 51 \mathrm{~km}$, for all channels. For the higher frequencies ( $\mathrm{Ku}$ and $\mathrm{Ka}$ band) we used data resampled to this resolution. The data are stored in Hierarchical Data Format (HDF), which is compatible with NASA HDF-EOS standard. In this study, we used L1b data, which contains values of brightness temperature, at vertical (V) and horizontal $(\mathrm{H})$ polarization, geometrically corrected and calibrated. Each file is $80 \mathrm{Mb}$, contains brightness temperature values along a $1450 \mathrm{~km}$ strip. The data was downloaded from NASA site (https://wist.echo.nasa.gov/api/).

Even when using 16-days repeat orbit data, the centers of AMSR-E image pixels are not coincident. This is due to AMSR-E conical scanning acquisition strategy (Kawanishi et al., 2003). Therefore, it is not possible to perform a pixel to pixel comparison between two images, even if they are from the same orbit. Instead, a drop-in-the-bucket method is usually preferred in time series analysis of AMSR-E data (Kawanishi et al., 2003). This method estimates the mean value of the brightness temperature of an area as the average of all the observations whose pixel centers are contained in this area. However, it is important to remark that this estimate includes brightness temperature observations from outside the area of interest. This error can be neglected when the study area is large and homogeneous, but is critical when comparing multitemporal data corresponding to relatively small area (i.e. a narrow river floodplain). 


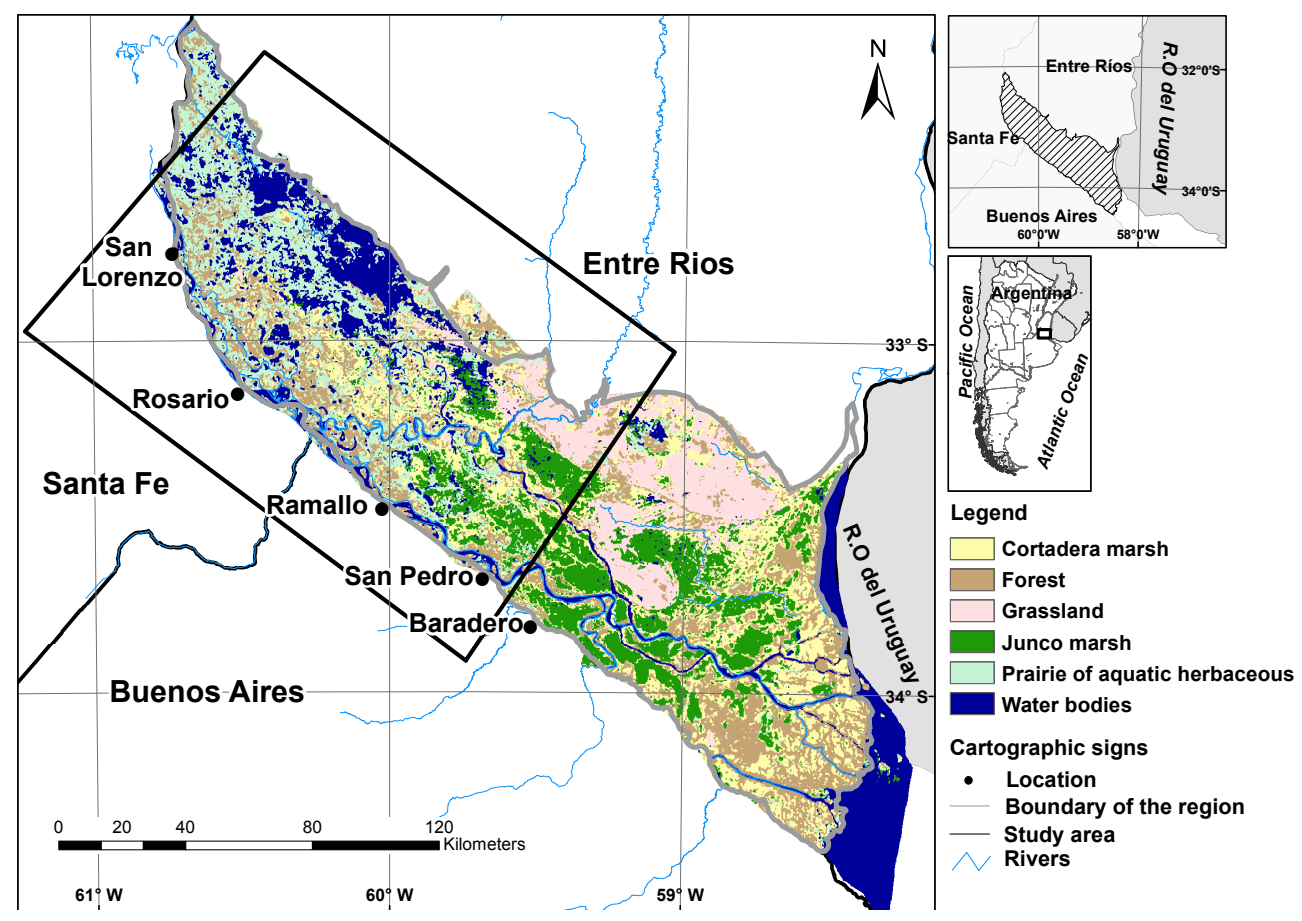

Fig. 1. Landcover map of Paraná River Delta. Main vegetation patterns mapped using SAC-C MMRS system (Salvia et al., 2009) are shown. The rectangular box indicates the area selected in this study.

Table 1. Summary of used data.

\begin{tabular}{lll}
\hline & Envisat ASAR, Wide Swath Mode & AMSR-E \\
\hline Pixel size & $75 \times 75 \mathrm{~m}$ & $29 \times 51 \mathrm{~km}$ \\
Operational Frequency & C band & X, Ku and Ka band \\
Available polarizations & HH & H and V \\
Acquisition dates & Non flooded: 10 Jun 2009 Flooded: 19 Aug 2009 21 Sep 2009 & 20 Aug 2009, 21 Sep 2009, 24 Nov 2009 \\
& 2 Dec 2009, 19 Dec 2009, 6 Jan 2010, 21 Apr 2010 & 10 Dec 2009, 11 Jan 2010, 17 Apr 2010 \\
\hline
\end{tabular}

Furthermore, these errors are proportional to the sum of the fractions of footprint areas that are outside the study area. In our case, since the area is narrow and the polarization difference of the wetland is large compared to the one of the continent, the overall effect is a reduction of the observed polarization difference.

In order to deal with this issue, we developed an ad hoc strategy to minimize the effects of this kind of errors in small areas. We extracted AMSR-E data from the rectangular box indicated in Fig. 1, which is larger than the specific study area limited by the Delta, since it includes a fraction of the continent. Then, we developed a methodology to estimate the polarization differences specifically contributed by the Delta area. To this aim, we used the polarization difference values averaged over the whole box of Fig. 1 and over some sample areas taken within the continent.
Multitemporal images of the observed polarization difference $\Delta T_{\mathrm{obs}}$ at $\mathrm{X}$ band are shown in Fig. 2. An evident increase of the polarization difference is observed after December 2009.

As far as active microwave signatures are concerned, this work uses Envisat ASAR medium resolution image products in Wide Swath image mode (ESA, 2007). For each date, there is a multilook ground range digital image. For this particular application, we selected $\mathrm{HH}$ polarization, considering the well known dynamic range of $\mathrm{HH}$ to changes in flood condition (Grings et al., 2005). Sample images of the area are shown in Fig. 3. The first image was collected on 10 June 2009, corresponding to a non-flooded condition, and was used as a reference. An evident change of the backscattering coefficient is observed in the subsequent two images. It is an increase for moderate flooding, and a decrease for intense flooding, as discussed in Grings et al. (2006). 

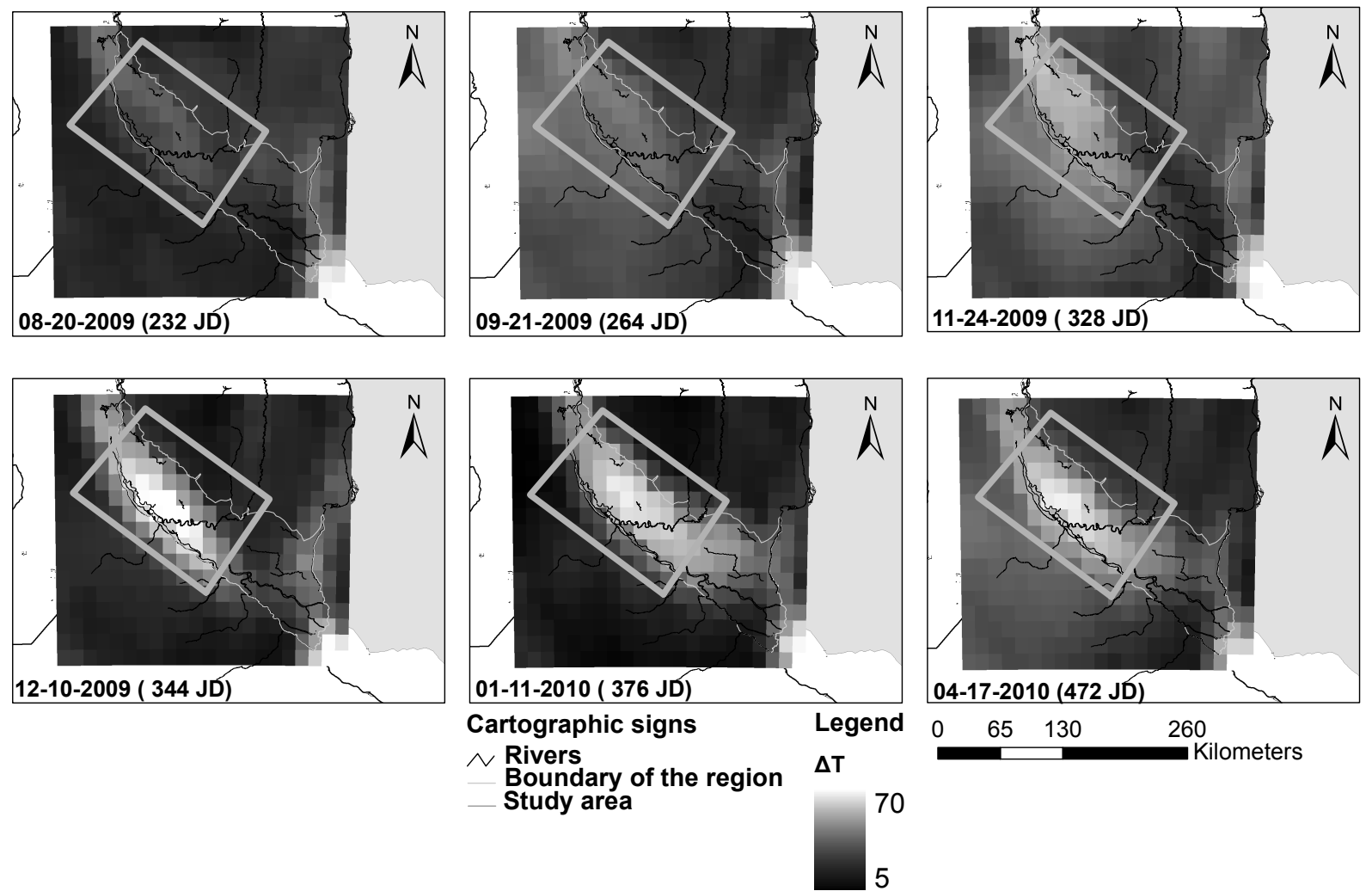

70

Fig. 2. AMSR-E images of $\Delta T$ at $X$ band in the Paraná River delta. Julian dates starting from 1 January 2009: 232, 264, 328 (upper figures), 344, 376, 472 (lower figures). The rectangular box indicates the area selected in this study.

In order to interpret the changes in the backscattering coefficient and in brightness temperature, we used both the landcover map of Fig. 1 and ancillary data. Among them, water level information is important. This variable was continuously monitored in five stations along the river: San Lorenzo, Rosario, Ramallo, San Pedro, and Baradero. The temporal trends of water level in the stations are shown in Fig. 4. The five trends are similar to each other, indicating the presence of a significant change in the hydrological condition of the whole watershed. In the figure, the acquisition dates of the AMSR-E images are marked with vertical lines. The water level corresponding to the alert level for the Delta in the stations is marked with horizontal lines. The alert level (the level for which the river starts to inundate the land) was reached approximately 350-400 days after 1 January 2009. This produced effects on both passive and active signatures, as can be detected in Figs. 2 and 3.

\subsection{Basic formulas}

Basically, the passive data have been analyzed using the simple model proposed by Sippel et al. (1994). The model has three end-members, that represent the contributions of water, non-flooded land, and inundated floodplain to the total observed polarization difference $\Delta T_{\mathrm{obs}}$,

$$
\begin{aligned}
& \Delta T_{\mathrm{obs}}=f_{\mathrm{w}} \Delta T_{\mathrm{w}}+f_{\mathrm{nf}} \Delta T_{\mathrm{nf}}+f_{\mathrm{f}} \Delta T_{\mathrm{f}} \\
& 1=f_{\mathrm{w}}+f_{\mathrm{f}}+f_{\mathrm{nf}}
\end{aligned}
$$

where $\Delta T_{\mathrm{obs}}$ is the polarization difference observed by the radiometer, $f_{\mathrm{w}}, f_{\mathrm{nf}}$ and $f_{\mathrm{f}}$ are the fractional areas of open water (rivers and lakes without emergent vegetation), nonflooded land, and seasonally flooded land, respectively, and $\Delta T_{\mathrm{w}}, \Delta T_{\mathrm{nf}}$, and $\Delta T_{\mathrm{f}}$ are the polarization difference values for open water, non-flooded land, and seasonally flooded land, respectively. Simultaneous solution of Eqs. (1) and (2) yields the following equation for the fraction of inundated floodplain $\left(f_{\mathrm{f}}\right)$ :

$$
f_{\mathrm{f}}=\frac{\Delta T_{\mathrm{obs}}-f_{\mathrm{w}} \Delta T_{\mathrm{w}}-\Delta T_{\mathrm{nf}}+f_{\mathrm{w}} \Delta T_{\mathrm{nf}}}{\Delta T_{\mathrm{f}}-\Delta T_{\mathrm{nf}}}
$$

The fractional area of flooded land expands during inundation with a concomitant reduction in the fractional area of non-flooded land. The algorithm is based on the following hypothesis: 

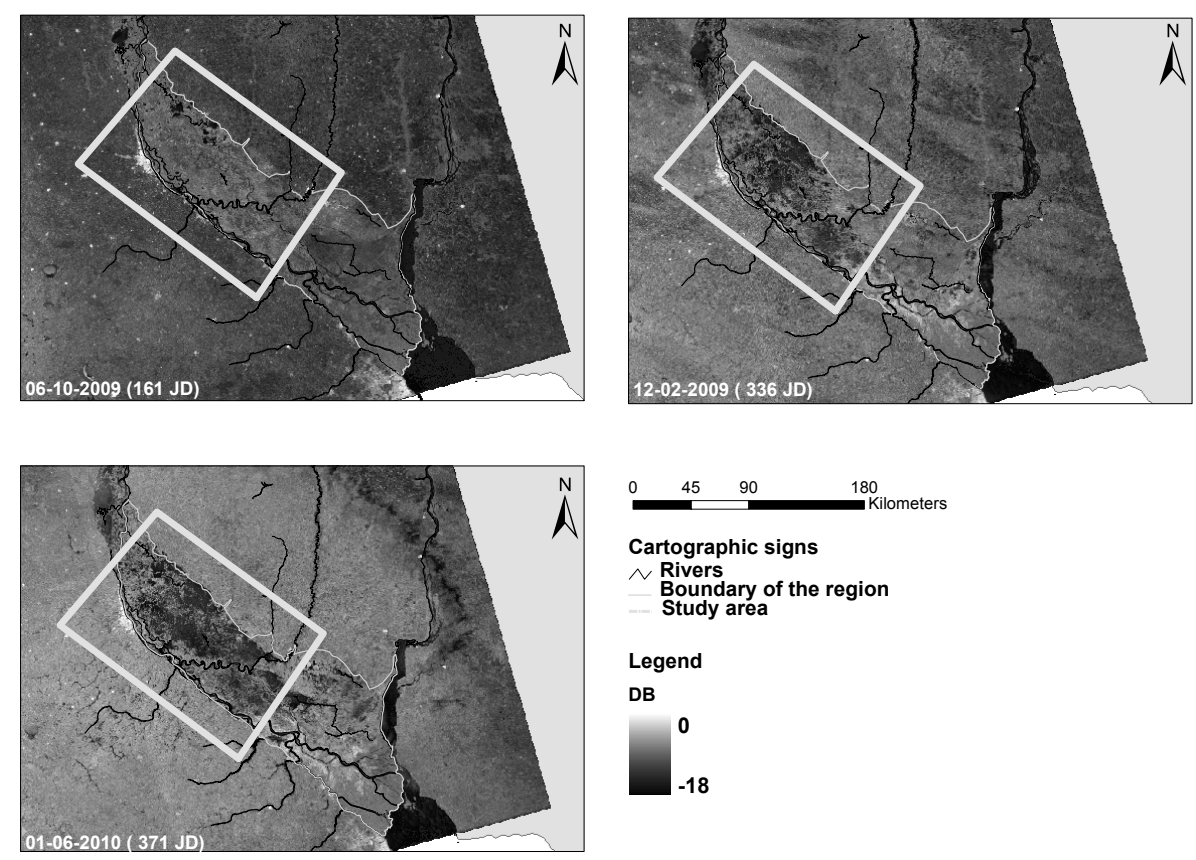

Fig. 3. Example of Envisat ASAR Wide Swath (HH polarization) images of the Paraná River delta used in this paper. Julian dates starting from 1 January 2009: 161, 336 (upper figures), 371 (lower figure). The rectangular box indicates the area selected in this study.

1. The temperature difference of water bodies at a given frequency, $\Delta T_{\mathrm{w}}$, is constant and known.

2. The temperature difference of non-flooded land, $\Delta T_{\mathrm{nf}}$, is constant and shows a unique value for all the vegetation types present in the area and can be estimated from images.

3. The fractional area of permanent water bodies is constant and known.

4. The temperature difference of flooded land, $\Delta T_{\mathrm{f}}$, is constant, shows a unique value for all the vegetation types present in the area, and can be estimated from images.

In Sippel et al. (1994), the objective was to estimate $f_{\mathrm{f}}$ from $\Delta T_{\text {obs. }}$. However, the hypothesis to consider $\Delta T_{\mathrm{f}}$ constant in time and the same for all the different kinds of vegetation inside the study area is debatable. Indeed, a specific section of Sippel et al. (1994) was dedicated to describe the statistical properties of the $\Delta T_{\mathrm{f}}$ estimated from images, since a large dispersion in its values were observed. In this work, we will assume that $\Delta T_{\mathrm{f}}$ is not constant in time, but is related to the water level, i.e. $\Delta T_{\mathrm{f}}=f(\mathrm{WL})$ : when $\mathrm{WL}=0$, $\Delta T_{\mathrm{f}}=\Delta T_{\mathrm{nf}}$ and for $\mathrm{WL}>h$, where $h$ is the mean vegetation height, $\Delta T_{\mathrm{f}}=\Delta T_{\mathrm{w}}$. The behavior of $\Delta T_{\mathrm{f}}(\mathrm{WL})$ in the range $0 \leqq \mathrm{WL} \leqq h$ is estimated by model simulations.
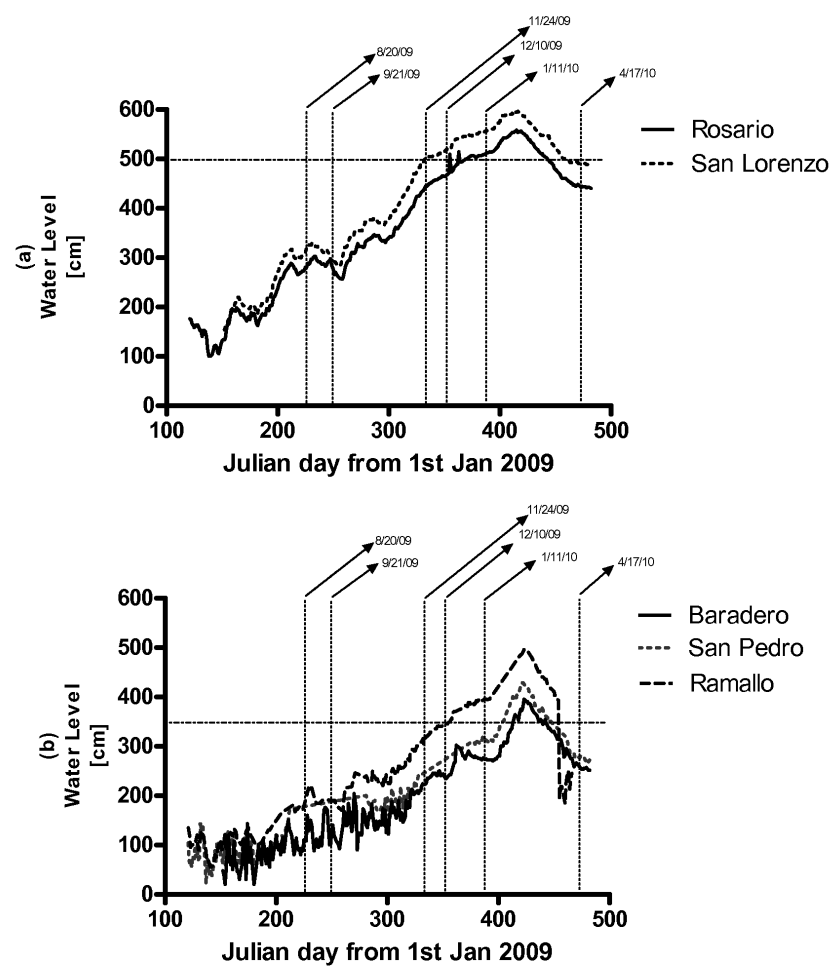

Fig. 4. Water level $(\mathrm{cm})$ measured in the five stations as a function of time. The horizontal lines indicates alert river water level and vertical dotted lines indicate AMSR-E acquisition dates. (a) Rosario and San Lorenzo and (b) Baradero, San Pedro and Ramallo 
Table 2. Input parameters to the interaction model.

\begin{tabular}{llll}
\hline & Parameter & Value & Observations \\
\hline General & Frequency & $10.8 \mathrm{GHz}, 18.7 \mathrm{GHz}, 36.6 \mathrm{GHz}$ & AMSR-E, X band, Ku band, Ka band \\
& Incidence angle & $55^{\circ}$ & AMSR-E \\
\hline Soil parameters & Soil moisture & $1.0 \mathrm{~cm}^{3} \mathrm{~cm}^{-3}$ & Flooded soil \\
& RMS height & $0.04 \mathrm{~cm}$ & Flooded soil \\
& Correlation length & $10 \mathrm{~cm}$ & Flooded soil \\
\hline \multirow{2}{*}{ Vegetation parameters } & Vegetation height & $200 \mathrm{~cm}$ & Cortadera marsh \\
& Maximum emerged Leaf Area Index & 5 & Mean LAI of cortadera marsh \\
& Leaf width & $2.5 \mathrm{~cm}$ & Cortadera marsh \\
& Leaf thickness & $0.02 \mathrm{~cm}$ & Cortadera marsh \\
& Leaf gravimetric moisture & $0.7 \mathrm{~g} \mathrm{~g}^{-1}$ & Cortadera marsh \\
& Maximum emerged stem height & $180 \mathrm{~cm}$ & Junco marsh \\
& Stem radius & $0.45 \mathrm{~cm}$ & Junco marsh \\
& Plant density & $90 \mathrm{plants} \mathrm{m}^{-2}$ & Junco marsh \\
& Stem gravimetric moisture & $0.7 \mathrm{~g} \mathrm{~g}^{-1}$ & Junco marsh \\
\hline
\end{tabular}

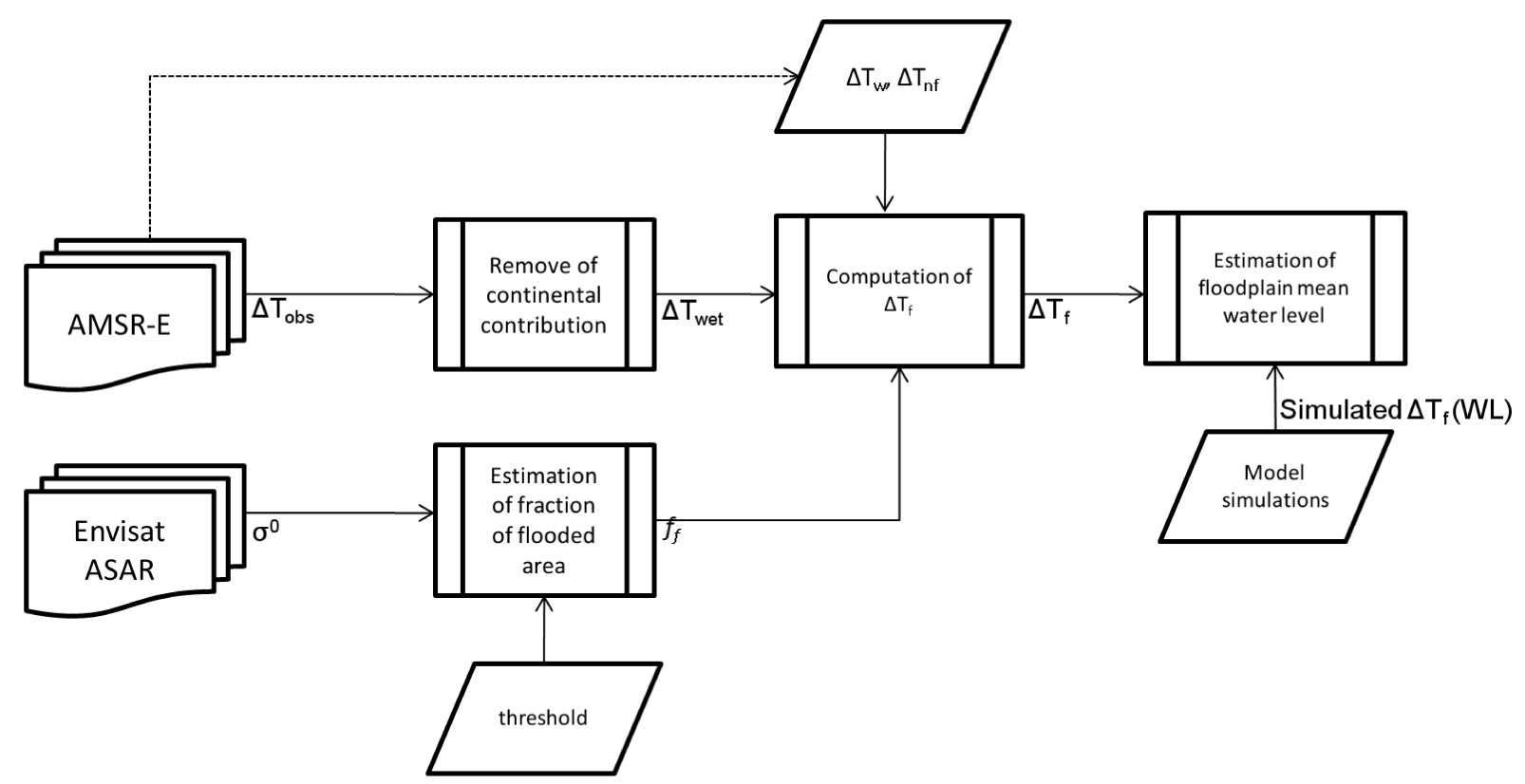

Fig. 5. Flow diagram of the methodology.

\subsection{Model simulations}

As it will be outlined in Sect. 2.5.6, we use a look-up table which associates $\Delta T_{\mathrm{f}}$ to water level (WL), for all the considered AMSR-E channels. The look-up table is obtained by model simulations. We used the vegetation model developed at Tor Vergata University. It is a discrete model based on the radiative transfer theory, including multiple scattering effects. The model is able to compute both the emissivity and the backscattering coefficient, and was adapted to several types of vegetation.
The modeling process is subdivided into various steps. First of all, the geometry of vegetation elements is selected. Stems are represented as dielectric cylinders, while leaves are represented as dielectric discs. The permittivity of elements is computed as a function of their moisture. Using electromagnetic approximations available in the literature, such as "Infinite Length" for cylinders and Physical Optics for discs, the extinction, absorption, and bistatic scattering cross sections of single elements are computed. Using a matrix algorithm which includes multiple scattering effects, the single contributions are combined, the bistatic scattering coefficient 
Table 3. Parameters of the water level retrieval algorithm.

\begin{tabular}{llrr}
\hline & & $\begin{array}{r}\Delta T_{\mathrm{nf}} \\
\text { (from model }\end{array}$ & $\begin{array}{r}\Delta T_{\mathrm{nf}} \\
(\text { from }\end{array}$ \\
& $\Delta T_{\mathrm{W}}[\mathrm{K}]$ & simulations) $[\mathrm{K}]$ & images) $[\mathrm{K}]$ \\
\hline X band & $97.0 \pm 3.2$ & 8.0 & $8.1 \pm 0.8$ \\
Ku band & $92.8 \pm 1.8$ & 4.0 & $5.2 \pm 0.4$ \\
Ka band & $88.2 \pm 4.2$ & 2.0 & $2.2 \pm 0.2$ \\
\hline
\end{tabular}

of the whole medium is computed, and the emissivity is obtained by using the energy conservation law. Details of the passive version of the model are available in Ferrazzoli and Guerriero (1996a) and Ferrazzoli and Guerriero (1996b). In the study area, the main vegetation is herbaceous, and the main species are junco and cortadera. For this type of vegetation, we adopted the vegetation dielectric and geometric characteristics already used in Grings et al. (2006) to simulate the changes in the backscattering coefficient of the herbaceous vegetation due to changes in the flood condition. The soil is represented as a half-space with rough interface. For inundated marshes, the soil has the permittivity of water and a low roughness. For junco marshes, vegetation elements are stems, represented as vertical dielectric cylinders. Their height is equal to the height of the emerged vegetation, while other variables are given on the basis of previous measurements (Grings et al., 2006, 2008). For cortadera marshes, which are essentially made of long leaves, vegetation elements are represented as dielectric discs. The maximum leaf area index in absence of flooding is equal to 5 . While the water level increases, the leaf area index is assumed to be reduced following a linear trend, consistent with the uniform distribution of biomass observed experimentally. The other variables are also assigned on the basis of previous measurements (Grings et al., 2006). The input variables to the model are given in Table 2.

\subsection{Methodology}

In order to deal with drop-in-the-bucket inherent errors associated to small areas already mentioned in Sect. 2.2, we developed a methodology to extract the polarization difference values of Paraná River delta area from a known larger area. This methodology is necessary, since it is not possible to have the same pixel centers at all dates, even using repeat pass orbit images. Moreover, the included area of continent varies from image to image and introduces several artifacts that degrade the quality of the estimation of the flooded fraction. In fact, the averaging is affected by the contribution of border pixels mainly dominated by crops, which present a low polarization difference.

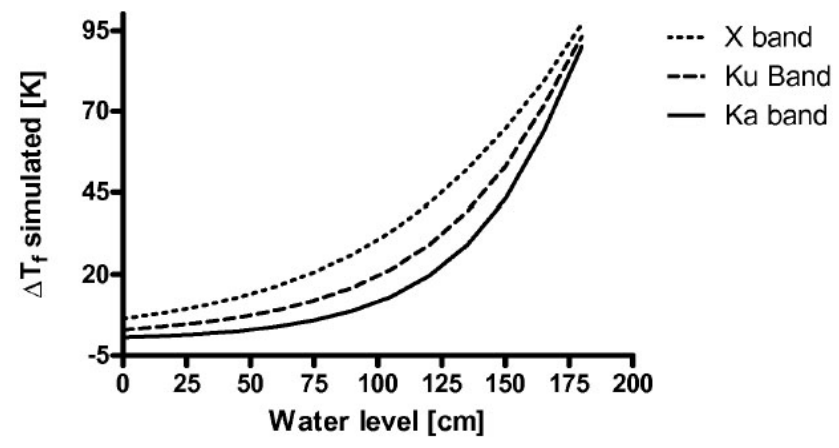

Fig. 6. Polarization difference in flooded marsh $\left(\Delta T_{\mathrm{f}}\right)$ simulated as a function of water level at $\mathrm{X}, \mathrm{Ku}$ and $\mathrm{Ka}$ band.

In order to solve this issue, we have selected an area larger than the river floodplain (see Fig. 1). For the rectangular box indicated in Fig. 1, we analyzed the data according to a method consisting of several steps.

1. The fraction of flooded area was estimated using ASAR;

2. The average polarization difference $\Delta T_{\mathrm{obs}}$ was computed using AMSR-E signatures at $\mathrm{X}, \mathrm{Ku}$ and $\mathrm{Ka}$ band;

3. The contribution of the continental part of the rectangular box was removed;

4. For all frequencies, the contributions of non-flooded areas $\Delta T_{\mathrm{nf}}$ and water bodies $\Delta T_{\mathrm{w}}$ were estimated;

5. The polarization difference $\Delta T_{\mathrm{f}}$ in flooded delta was estimated;

6. Inverting a look up table based on model simulations, $\Delta T_{\mathrm{f}}$ values were converted into corresponding water level WL values.

The various steps of the procedure are shown in Fig. 5 and described below.

\subsubsection{Estimation of the fraction of flooded area $f_{\mathrm{f}}$}

The fraction of flooded area is estimated from pairs of Envisat ASAR WS images. The first image of the pair is the reference one collected on Julian day 161, that is in a dry period, and the second one was collected on six different dates during the flooding.

Since the soil is covered by vegetation and it is wet even in normal conditions, the change of the backscattering coefficient $\left(\sigma^{0}\right)$ between images was associated to a change in water level. There are previous results that support this statement in wetland marshes worldwide (Hess et al., 1995) and in particular, in Paraná River wetland marshes observed by Envisat ASAR (Grings et al., 2005, 2009; Salvia et al., 2009). 
Since the complete flood event we are analyzing lasted 9 months, we compared images from different seasons. Therefore, one important hypothesis is that $\mathrm{C}$ band $\sigma^{0}$ of the studied vegetation does not depends strongly on season; therefore, the changes in $\mathrm{C}$ band $\sigma^{0}$ can be unequivocally interpreted as changes in the flood condition. For the Paraná River Delta marshes, that are perennial, there is experimental evidence that the $\mathrm{C}$ band $\sigma^{0}$ of the vegetation measured with Envisat ASAR does not change significantly between seasons (Pratolongo, 2005).

According to previous works, in predominantly vertical wetland marshes observed at $\mathrm{C}$ band, a change in the flood condition can produce either an increase or a decrease in the overall $\sigma^{0}$ of the area (Grings et al., 2008). This is due to a complex interaction between vegetation bistatic scattering and vegetation attenuation (Grings et al., 2006). In fact, flooding reduces the surface contribution, due to the decrease of roughness, but increases the double bounce. Overall, moderate flooding produces an increase of backscattering coefficient, due to the increase of double bounce. However, if the increase of water level submerges most of vegetation, the overall effect is a decrease of backscattering coefficient.

We exploited these properties in order to identify the pixels affected by flooding. We considered three different thresholds in $\sigma^{0}$ variation with respect to the image of day 161 , taken as reference. A pixel was assumed to be flooded for variations higher than:

- $1.0 \mathrm{~dB}$ increase or $1.0 \mathrm{~dB}$ decrease,

- $1.5 \mathrm{~dB}$ increase or $1.5 \mathrm{~dB}$ decrease,

$-2.0 \mathrm{~dB}$ increase or $2.0 \mathrm{~dB}$ decrease.

Of course, higher thresholds correspond to more severe criteria. As it will be shown in the following, they lead to higher values of water level in the pixels labeled as "flooded".

\subsubsection{Computation of the overall polarization difference $\Delta T_{\mathbf{o b s}}$}

For the three selected AMSR-E channels, and for all the listed dates the polarization difference $\Delta T_{\mathrm{obs}}$, was computed by averaging among all the pixels whose centers are inside the rectangular box of Fig. 1. These values resulted from a complex combination of various contributions: flooded marsh, non flooded marsh, water body and continental areas.

\subsubsection{Removal of the continent part and estimation of the polarization difference of the wetland $\Delta T_{\text {wet }}$}

We estimated the polarization differences of the wetland, $\Delta T_{\text {wet }}$, from the polarization differences of the original box, $\Delta T_{\text {obs. }}$ In order to remove the effect of the continent contribution, we estimated the polarization difference of the continental part, $\Delta T_{\mathrm{c}}$, considering samples from both the Northeast and Southwest side of the river floodplain. Using this result, we estimated the polarization difference values of the wetland, $\Delta T_{\text {wet }}$, as:

$\Delta T_{\text {wet }}=\frac{\Delta T_{\mathrm{obs}}-f_{\mathrm{c}} \Delta T_{\mathrm{c}}}{1-f_{\mathrm{c}}}$

where $f_{\mathrm{c}}$ is the fraction of continent in the rectangular study area of Fig. 1. In order to estimate $f_{\mathrm{c}}$, we subtracted the Paraná River Delta area to the total area (see Fig. 1). Using this procedure, we found $f_{\mathrm{c}}=0.51$.

\subsubsection{Estimation of non-flooded area $\left(\Delta T_{\mathrm{nf}}\right)$ and water $\left(\Delta T_{\mathrm{w}}\right)$ polarization differences}

As stated before, the temperature difference of non-flooded land, $\Delta T_{\text {nf }}$ was considered constant for each frequency. In order to estimate this parameter, we applied two different methods: (i) we considered 20 AMSR-E measured values extracted in the drought period for nearly homogeneous vegetated pixels; and (ii) we used model simulations for the nonflooded case. Both estimates are reported in Table 3. For the measured values the standard deviation is also given. Simulated and measured values are in agreement.

It is well established that the polarization difference of calm water, $\Delta T_{\mathrm{w}}$, depends on frequency, observation angle and surface roughness (Ulaby et al., 1986). We estimated this value for each frequency using the same AMSR-E images.To this end, we considered samples from a large permanent endorheic lake (Laguna de Mar Chiquita), located at a distance of about $300 \mathrm{~km}$ from the study site. The obtained values of $\Delta T_{\mathrm{w}}$ are also given in Table 3.

\subsubsection{Computation of the polarization difference in flooded marsh $\left(\Delta T_{\mathrm{f}}\right)$}

As we discussed before, we assumed that the polarization differences of the flooded marshes, $\Delta T_{\mathrm{f}}$, cannot be considered constant for all dates and are in fact function of water level. Therefore, the formulas of Sippel et al. (1994) were used inversely, in order to estimate $\Delta T_{\mathrm{f}}$ as a function of $\Delta T_{\text {wet }}$. Then, Eq. (1) was rewritten as:

$\Delta T_{\mathrm{f}}=\frac{\Delta T_{\mathrm{wet}}-f_{\mathrm{w}} \Delta T_{\mathrm{w}}-\Delta T_{\mathrm{nf}}+f_{\mathrm{w}} \Delta T_{\mathrm{nf}}}{f_{\mathrm{f}}}+\Delta T_{\mathrm{nf}}$

In summary, we estimated $\Delta T_{\mathrm{f}}$, using

- The polarization differences of the wetland measured by $\operatorname{AMSR-E}\left(\Delta T_{\text {wet }}\right)$;

- The flooded fraction of the wetland derived from Envisat ASAR data $\left(f_{\mathrm{f}}\right)$;

- The fraction of permanent water bodies derived from SAC-C data $\left(f_{\mathrm{w}}\right)$ (Salvia et al., 2009)

- The polarization difference of water $\left(\Delta T_{\mathrm{w}}\right)$ and that of non-flooded vegetation $\left(\Delta T_{\mathrm{nf}}\right)$ which are given in Table 3. 

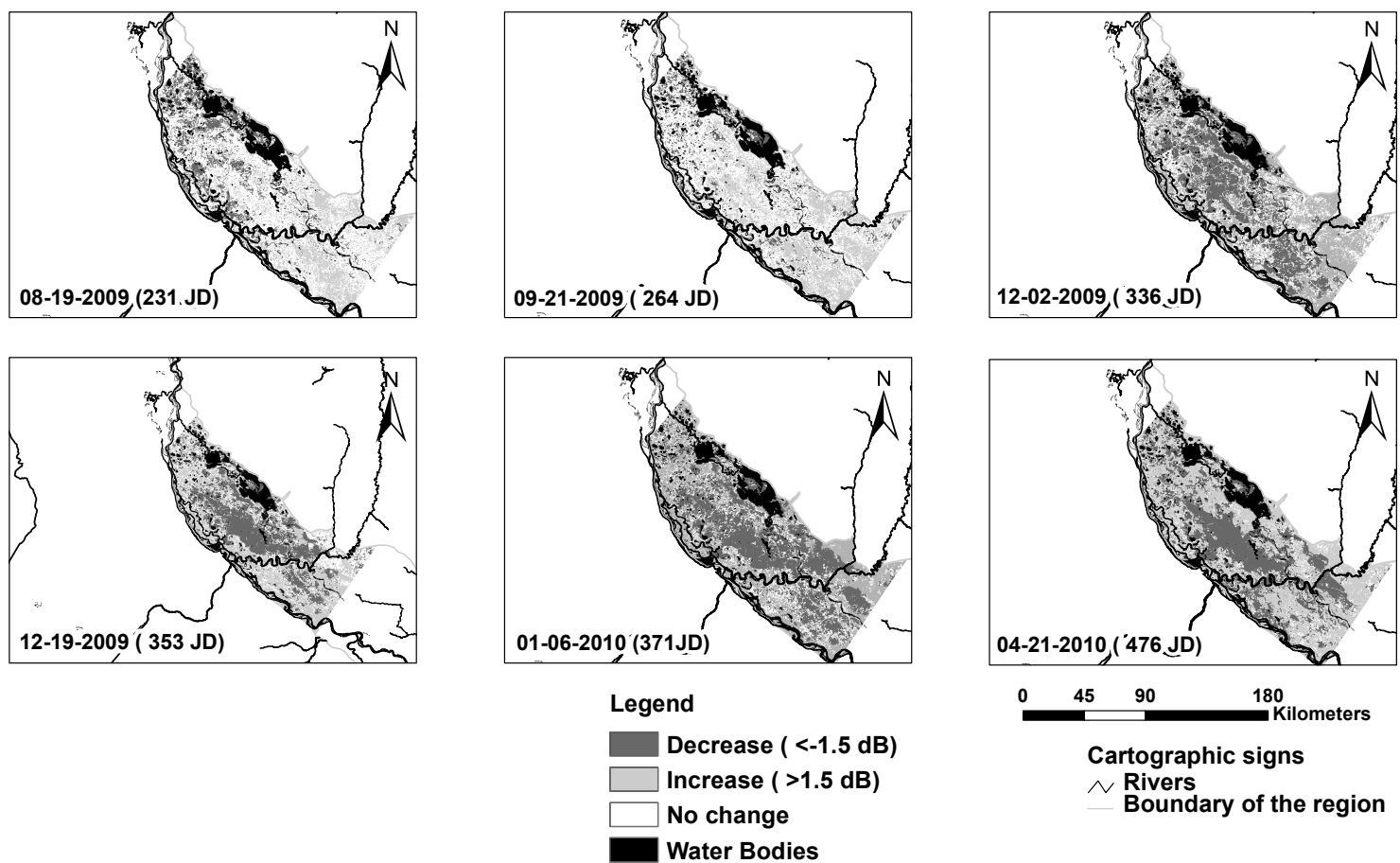

Fig. 7. Maps of $\sigma^{0}$ change derived from ASAR images for six dates. Julian dates starting from 1 January 2009: 231, 264, 336 (top figures), 353, 371, 476 (bottom figures).

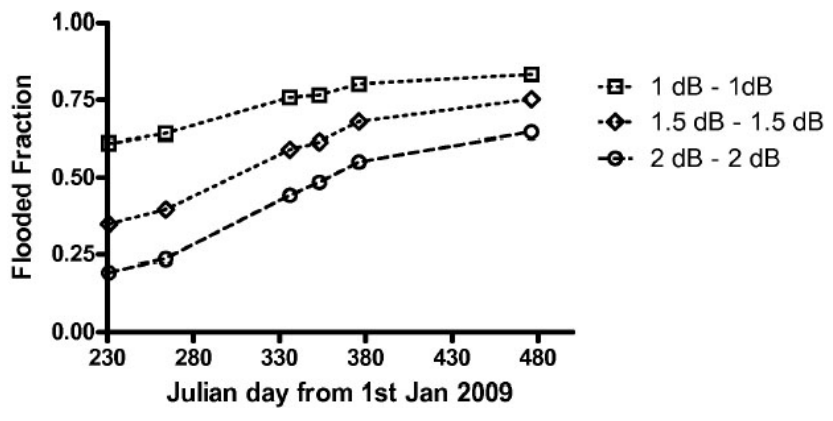

Fig. 8. Fraction of flooded area estimated from ASAR images for six dates and three different thresholds

\subsubsection{Estimation of water level in flooded marsh (WL)}

Finally, we estimated the water level as a function of the polarization difference of flooded marshes $\left(\Delta T_{\mathrm{f}}\right)$, using a twostep procedure. The first step consisted in generating a lookup table which associated $\Delta T_{\mathrm{f}}$ to water level (WL), for the considered AMSR-E channels. The second step essentially consisted in an inversion of the relationship defined previously. To establish the functional form of the dependence of $\Delta T_{\mathrm{f}}$ on WL, we used the emission model summarized in Sect. 2.4. For cortadera marshes, an increase of water level produces a decrease of emerged Leaf Area Index with respect to its maximum value. For junco marshes, the emerged stem height decreases with water level. The total polarization dif- ference was finally computed by averaging the contributions of junco and cortadera marshes. The results are presented in Fig. 6. As expected, $\Delta T_{\mathrm{f}}$ increases with increasing water level. The slope is dependent on frequency and on the water level itself.

The water level values of Fig. 6 were obtained using the data of Table 2 as input, for both cortadera and junco marshes. The inputs were assigned on the basis of previous field work (Grings et al., 2006). Among the inputs variables, the plant density is critical, since influences the emissivity and is subject to significant statistical fluctuations. The average value in Table 2 is 90 plants $\mathrm{m}^{-2}$, but measurements shown variations in the range $70-110$ plants $\mathrm{m}^{-2}$. Using the same model, we estimated that the corresponding maximum variations of $\Delta T_{\mathrm{f}}$ are equal to $\pm 8 \mathrm{~K}$ at $\mathrm{X}$ band, $\pm 7 \mathrm{~K}$ at $\mathrm{Ku}$ band and $\pm 6 \mathrm{~K}$ at Ka band.

Then, in order to estimate the mean water level inside our study area, the relations of Fig. 6 were inverted. To this end, 2nd degree polynomials were fitted to the model outputs, so that an inverse relation between water level and $\Delta T_{\mathrm{f}}$ was obtained for each frequency. If the trends of Fig. 6 are inverted, the maximum variations of water level due to uncertainty in plant density are: $\pm 15 \mathrm{~cm}$ at $X$ band, $\pm 14 \mathrm{~cm}$ at Ku band, and $\pm 12 \mathrm{~cm}$ at Ka band. 


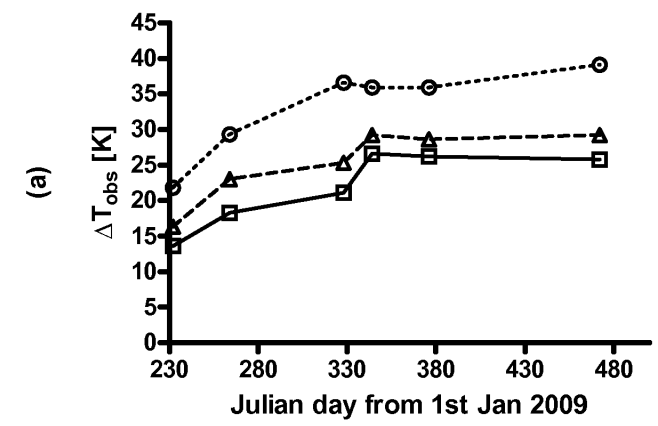

$$
\begin{aligned}
& \text { - }-X \text { band } \\
& \text {-4. Ku Band } \\
& \text { \# Ka band }
\end{aligned}
$$

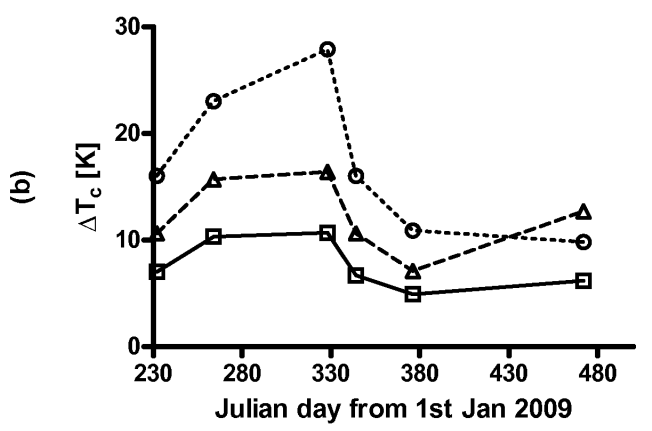

$$
\begin{aligned}
& \text {-๑- X band } \\
& \text {-. Ku Band } \\
& \text { ๘ Ka band }
\end{aligned}
$$

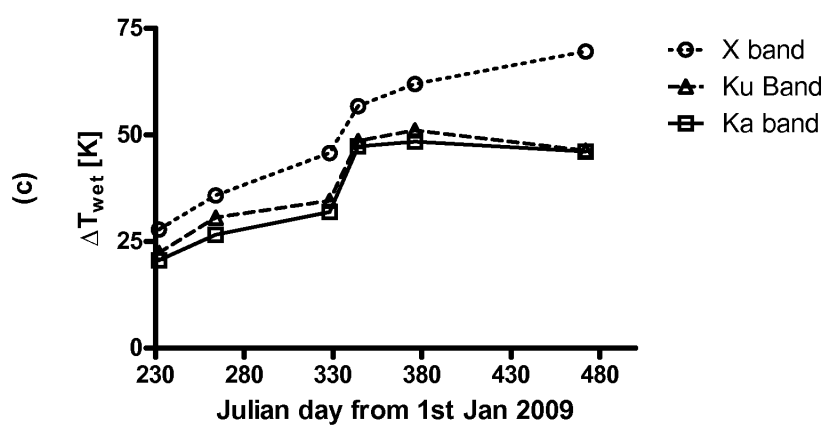

Fig. 9. Polarization differences as a function of time for the three AMSR-E considered bands. (a): overall measured $\Delta T_{\mathrm{obs}}$ (b): continent $\Delta T_{\mathrm{c}}$. (c): wetland $\Delta T_{\text {wet. }}$

\section{Results}

Applying the procedure described in Sect. 2.5.1, we derived maps of flooded areas from ASAR images. First of all, for each SAR pixel, we considered the variations of backscattering coefficient with respect to the image of 10 June 2009, taken as a reference. For the six dates listed in Sect. 2.2, maps of backscattering variations are shown in Fig. 7.

Then, for the three thresholds given in Sect. 2.5.1, we estimated the flooded fraction for the six images considering all the pixels that present a change higher than the given thresholds as flooded pixels. Results are shown in Fig. 8. As expected, for each date the larger thresholds are exceeded for a lower percentage of pixels. The effect of the selected threshold is reduced in the later dates, when the flood event is intense that a large fraction of pixels are labeled as flooded in any case. Due to the long term characteristics of this flood-
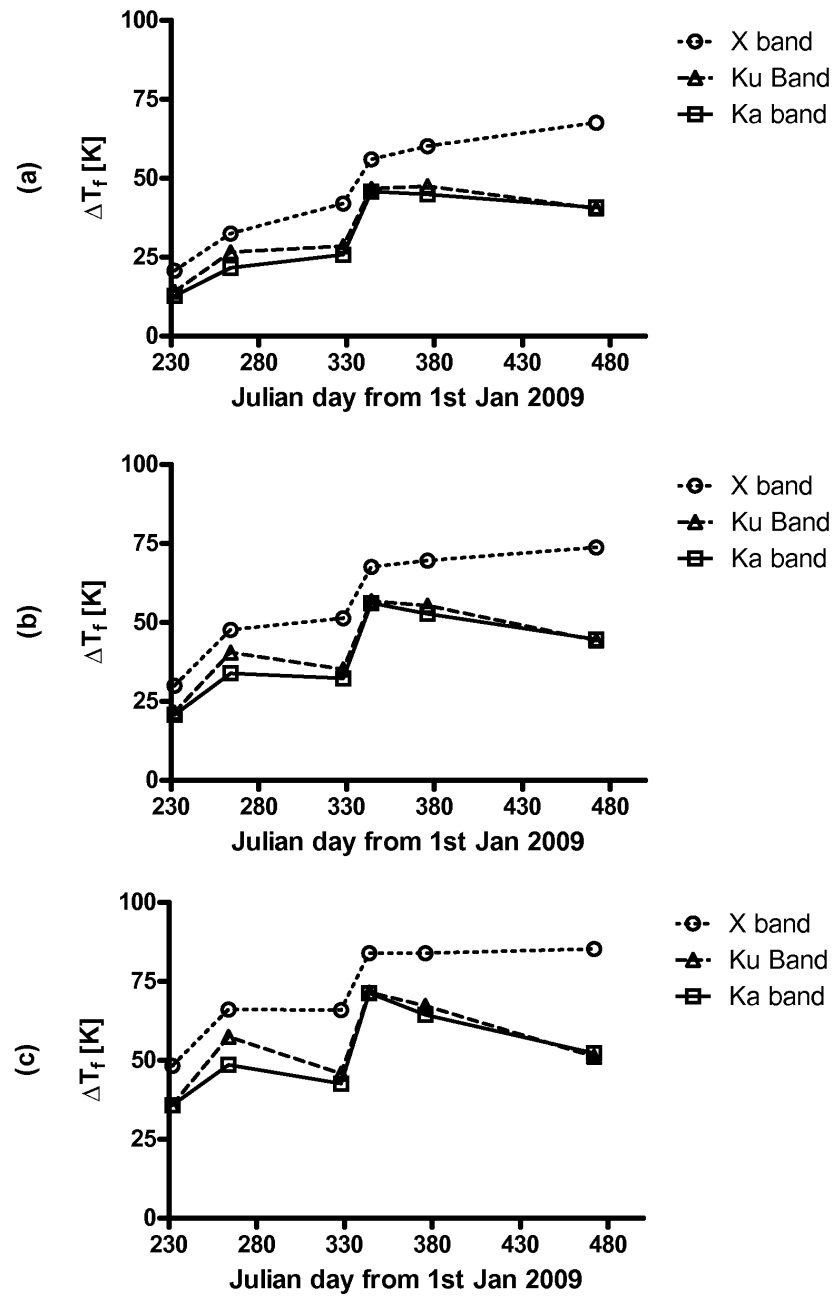

Fig. 10. $\Delta T_{\mathrm{f}}$ as a function of time for the three frequencies and for three different thresholds. (a) $1 \mathrm{~dB}$, (b) $1.5 \mathrm{~dB}$ and (c) $2 \mathrm{~dB}$

ing process, the temporal variations are quite slow. The obtained values of $f_{\mathrm{f}}$ were associated to AMSR-E images collected in nearly coincident dates (see the corresponding list in Sect. 2.2). However, since the maximum temporal shift between ASAR and AMSR-E acquisitions was equal to 9 days and the temporal variations of $f_{\mathrm{f}}$ are slow, the errors associated to these shifts can be neglected.

Then, in order to estimate the $\Delta T_{w e t}$ of the area of river basin under study, we applied the methodology described in Sects. 2.5.2 and 2.5.3 for the case of $1.5 \mathrm{~dB}$ threshold. The obtained trends of $\Delta T_{\mathrm{obs}}, \Delta T_{\mathrm{c}}$ and $\Delta T_{\mathrm{wet}}$ as a function of time are shown in Fig. 9. The time is given in Julian dates, starting from 1 January 2009.

As expected, $\Delta T_{\text {obs }}$ (Fig. 9a) presents a complex behavior, related to the combined temporal trends of events both in the river floodplain and in the continent. The $\Delta T_{\mathrm{c}}$ value, obtained from significant samples of the main continent landcover, shows its own temporal trend mainly related to agricultural exploitation, particularly after Julian Day 330 (Late 

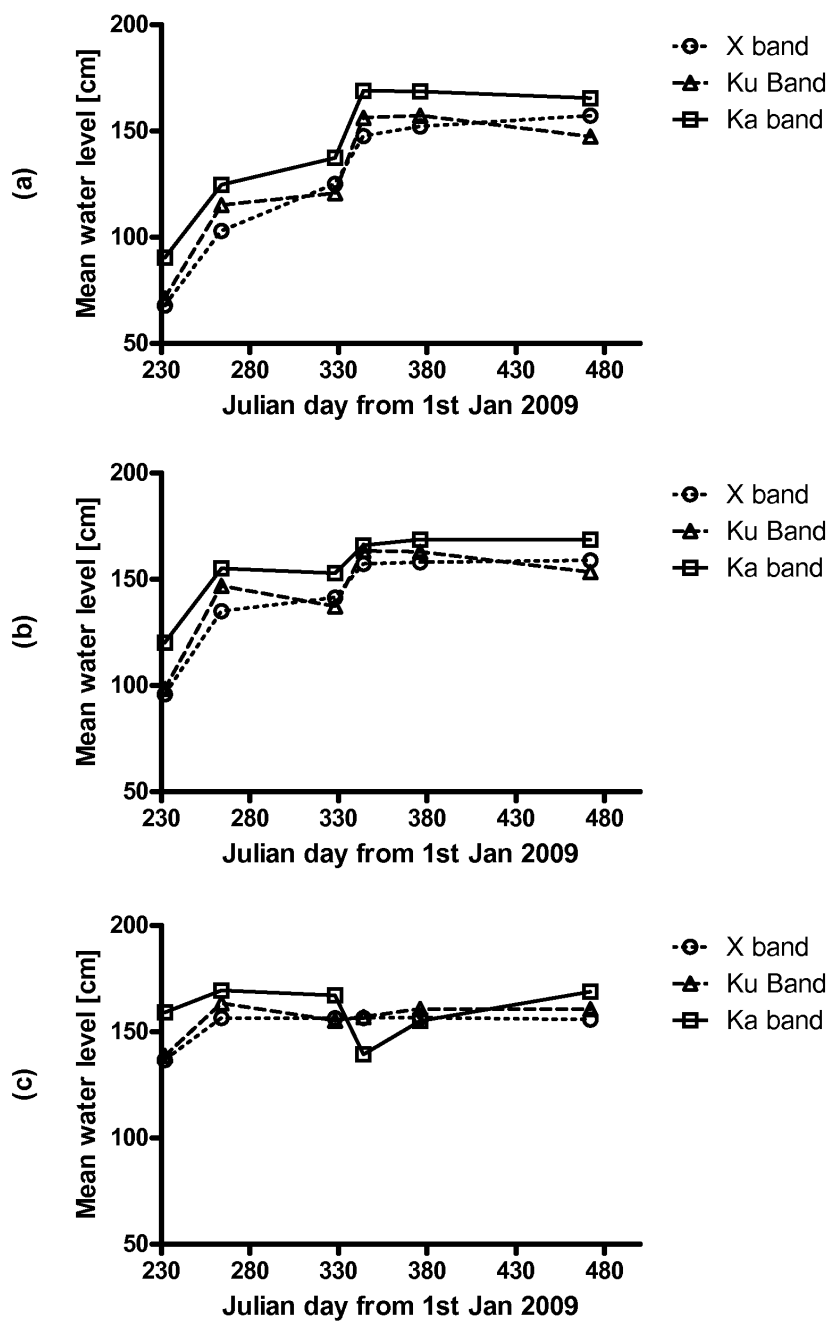

Fig. 11. Mean water level within the studied floodplain area as a function of time, estimated using $\Delta T_{\mathrm{f}}$ values (Fig. 10) and model simulations (Fig. 6) for three different thresholds. (a) $1 \mathrm{~dB}$, (b) 1.5 $\mathrm{dB}$ and (c) $2 \mathrm{~dB}$

Spring in Argentina) (Fig. 9b). It can be seen that after the removal of the continent area, the $\Delta T_{\text {wet }}$ of the wetland area shows a generally increasing trend and an abrupt increase from Julian date 328 to Julian date 344 (Fig. 9c).

To estimate the $\Delta T_{\mathrm{f}}$ values from $\Delta T_{\text {wet }}$ and $f_{\mathrm{f}}$, we used Eq. (5) and the values of $\Delta T_{\mathrm{nf}}$ and $\Delta T_{\mathrm{w}}$ given in Table 3, according to the procedure described in Sect. 2.5.5. The results are shown in Fig. 10. A step between Julian date 328 (24 November 2009) and Julian date 344 (10 December 2009) is observed also in this case. There is a marked difference between $\mathrm{X}$ band and higher frequencies, particularly in the later dates.

Using the methodology depicted in Sect. 2.5.6 and the results of Fig. 6, we estimated the mean water level inside the study area as a function of $\Delta T_{\mathrm{f}}$. The results are shown in Fig. 11.
Also the results obtained by repeating the procedure with $1.0 \mathrm{~dB}$ and $2.0 \mathrm{~dB}$ thresholds (both as increase and as decrease) are reported. Some features are observed in this Figure. In the cases of lower thresholds, such as $1.0 \mathrm{~dB}$ and $1.5 \mathrm{~dB}$, there is a temporal increase of estimated water level in the marshes, which is simultaneous to the increases in the measured water level in the river (Fig. 4) and estimated flood fraction (Fig. 8). This means that the event produces both an increase in the fraction of pixels labeled as "flooded" and an increase in the estimated water level within them. In the case of the $2.0 \mathrm{~dB}$ threshold, the estimated water level is high even in the early dates, but this level is exceeded only in a small fraction of pixels (see Fig. 8). In Fig. 10, the $\Delta T_{\mathrm{f}}$ obtained at $\mathrm{X}$ band is higher than the ones at $\mathrm{Ku}$ and $\mathrm{Ka}$ band. particularly in the later dates, when there is a short emerged vegetation. In these conditions, the increase of attenuation with frequency is more evident. This effect is considered by the model, so that the estimated trends of WL are similar for the three selected frequency channels (Fig. 11).

The selection of the $1.5 \mathrm{~dB}$ threshold is a compromise between the requirement of an effective monitoring of water level variations and image radiometric uncertainties for a given equivalent number of looks $(\sim 21$ for Envisat WS images). Higher thresholds produces a rapid saturation and lower thresholds are constrained by radiometric uncertainties.

\section{Conclusions}

In this work, we presented a methodology to estimate the fraction of flooded area and the mean water level inside a wetland using active and passive microwave orbital systems. The methodology is based on the quasi-simultaneous measurements of the radiometric polarization difference and the differences of the backscattering coefficient with respect to a reference image. Using the differences of backscattering coefficients, the fraction of flooded area as a function of time was obtained. Then the polarization difference of the flooded vegetation was estimated and finally, with the aid of interaction models, the mean water level of the wetland area was obtained.

This methodology makes use of ancillary data, such as a landcover map that characterizes the main vegetation types present in the area, and exploits an interaction model that simulates the polarization difference of the vegetation at various frequencies and for different water levels.

A complete validation of the results over the whole area is not feasible. However, a comparison with in situ data of river water level measured at five stations is consistent. During the time in which the in situ measured water level increases, the fraction of flooded area increases regularly, while the water level estimated in the marshes increases slightly, with a step increment occurring in the Julian days from 328 to 344, when the river reached the alert level. Moreover, the algorithm was 
applied using three different AMSR-E frequencies showing very close values of mean water level. Although the behavior of $\Delta T_{\mathrm{f}}$ at $\mathrm{X}$ band differs from the other two, the trends of WL are similar.

The use of both active and passive data allows us to estimate also the water level in flooded vegetation, but limits the temporal resolution. As a future development, we plan to use the water level estimated using both passive and active signatures as an initial value in the algorithm of Sippel et al. (1994) that uses passive data only. This can allow us to exploit the temporal resolution of passive data with a periodic adjournment (using both passive and active data) of water level information.

Acknowledgements. The authors specially thank the European Space Agency (ESA) for the continuous support through AO 667 supported project, the National Commission for Space Activities (CONAE) for the optical data, the National Water Institute (INA) and the National Hydrologic Service (SHN) for providing us river water levels and precipitation data. This work was funded by the Agencia Nacional de Promocion Cientifica y Tecnologica (ANPCyT) (PICT 1203) and MinCyT-CONAE-CONICET project 12.

Edited by: N. Verhoest

\section{References}

Alsdorf, D. E., Rodríguez, E., and Lettenmaier, D. P.: Measuring surface water from space, Rev. Geophys., 34, 1-24, doi:10.1029/2006RG000197, 2007.

Caizzone, S., Ferrazzoli, P., Guerriero, L., and Pierdicca, N.: Modeling backscattering variations due to flooding over vegetated surfaces, Italian J. Remote Sens., 3, 25-37, 2009.

Choudhury, B. J.: Monitoring global land surface using Nimbus$737 \mathrm{GHz}$ data Theory and examples, Int. J. Remote Sens., 10, 1579-1605, 1989.

ESA: ASAR product handbook, Tech. rep., European Space Agency (ESA), 2007.

Ferrazzoli, P. and Guerriero, L.: Passive microwave remote sensing of forests: a model investigation,, IEEE T. Geosci. Remote Sens., 34, 433-443, doi:10.1109/36.485121, 1996a.

Ferrazzoli, P. and Guerriero, L.: Emissivity of vegetation: theory and computational aspects, J. Electromagnet. Wave., 10, 609628, doi:10.1163/156939396X00559, 1996b.

Ferrazzoli, P., Guerriero, L., Paloscia, S., Pampaloni, P., and Solimini, D.: Modeling polarization properties of emission from soil covered with vegetation,, IEEE T. Geosci. Remote Sens., 30, 157-165, doi:10.1109/36.124226, 1992.

Grings, F., Ferrazzoli, P., Karszenbaum, H., Tiffenberg, J., Kandus, P., Guerriero, L., and Jacobo-Berrles, J.: Modeling temporal evolution of junco marshes radar signatures,, IEEE T. Geosci. Remote Sens., 43, 2238-2245, doi:10.1109/TGRS.2005.855067, 2005.

Grings, F., Ferrazzoli, P., Jacobo-Berlles, J., Karszenbaum, H., Tiffenberg, J., Pratolongo, P., and Kandus, P.: Monitoring flood condition in marshes using EM models and Envisat ASAR observations,, IEEE T. Geosci. Remote Sens., 44, 936-942, doi:10.1109/TGRS.2005.863482, 2006.
Grings, F., Ferrazzoli, P., Karszenbaum, H., Salvia, M., Kandus, P., Jacobo-Berlles, J., and Perna, P.: Model investigation about the potential of $\mathrm{C}$ band SAR in herbaceous wetlands flood monitoring, Int. J. Remote Sens., 29, 5361-5372, doi:10.1080/01431160802036409, 2008.

Grings, F., Salvia, M., Karszenbaum, H., Ferrazzoli, P., Kandus, P., and Perna, P.: Advances in radar remote sensing of wetland ecosystems: Combination of satellite observations, field data and em Models, J. Environ. Manage., 90, 2189-2198, 2009.

Hamilton, S., Sippel, S. J., and Melack, J. M.: Comparison of inundation patterns among major South American floodplains, J. Geophys. Res., 107, 1-14, doi:10.1029/2000jd000306, 2002.

Hess, L., Melack, J., Filoso, S., and Wang, Y.: Delineation of inundated area and vegetation along the Amazon floodplain with the SIR-C synthetic aperture radar,, IEEE T. Geosci. Remote Sens., 33, 896-904, doi:10.1109/36.406675, 1995.

Jackson, T. J. and Schmugge, T. J.: Vegetation effects on the microwave emission from soils, Remote Sens. Environ., 36, 203212, 1991.

Kawanishi, T., Sezai, T., Ito, Y., Imaoka, K., Takeshima, T., Ishido, Y., Shibata, A., Miura, M., Inahata, H., and Spencer, R.: The Advanced Microwave Scanning Radiometer for the Earth Observing System (AMSR-E), NASDA's contribution to the EOS for global energy and water cycle studies, IEEE T. Geosci. Remote Sens., 41, 184-194, doi:10.1109/TGRS.2002.808331, 2003.

Kerr, Y. and Njoku, E.: A semiempirical model for interpreting microwave emission from semiarid land surfaces as seen from space, IEEE T. Geosci. Remote Sens., 28, 384-393, doi:10.1109/36.54364, 1990.

Le Toan, T., Laur, H., Mougin, E., and Lopes, A.: Multitemporal and dual-polarization observations of agricultural vegetation covers by X-band SAR images, IEEE T. Geosci. Remote Sens., 27, 709-718, doi:10.1109/TGRS.1989.1398243, 1989.

Matgen, P., Schumann, G., Henry, J., Hoffmann, L., and Pfister, L.: Integration of SAR derived river inundation areas, high-precision topographic data and flood propagation models: a step towards effective, near real-time flood management, Int. J. Appl. Earth Obs., 9(3), 247-263, doi:10.1016/j.jag.2006.03.003, 2007.

Paloscia, S. and Pampaloni, P.: Microwave polarization index for monitoring vegetation growth, IEEE T. Geosci. Remote Sens., 26, 617-621, doi:10.1109/36.7687, 1988.

Paloscia, S., Pampaloni, P., Chiarantini, L., Coppo, P., Gagliani, S., and Luzi, G.: Multifrequency passive microwave remote sensing of soil misture and roughness, Int. J. Remote Sens., 14, 467-483, 1993.

Pappenberger, F., Frodsham, K., Beven, K., Romanowicz, R., and Matgen, P.: Fuzzy set approach to calibrating distributed flood inundation models using remote sensing observations, Hydrol. Earth Syst. Sci., 11, 739-752, doi:10.5194/hess-11-739-2007, 2007.

Parkinson, C.: Aqua: an Earth-Observing Satellite mission to examine water and other climate variables, IEEE T. Geosci. Remote Sens., 41, 173-183, doi:10.1109/TGRS.2002.808319, 2003.

Parmuchi, G., Karszenbaum, H., and Kandus, P.: Mapping the Paraná River delta wetland using multitemporal RADARSAT/SAR data and a decision based classifier, Can. J. Remote Sens., 28, 175-186, 2002.

Pratolongo, P.: Dinámica de comunidades herbáceas del bajo delta del río paraná sujetas a diferentes regímenes hidrológicos y su 
monitoreo mediante sensores remotos, Ph.D. thesis, Departamento de Ecología Genética y Evolución Facultad de Ciencias Exactas y Naturales Universidad de Buenos Aires, 2005.

Prigent, C., Papa, F., Aires, F., Rossow, W. B., and Matthews, E.: Global inundation dynamics inferred from multiple satellite observations, 1993-2000, J. Geophys. Res., 112, 113-129, 2007.

Salvia, M., Kandus, P., Karszenbaum, H., and Grings, F.: Optical and radar satellital data for mapping and monitoring wetland macrosystems, Revista Española de Teledeteccion, 31, 35-51, 2009.

Sippel, S. J., Hamilton, S., Melack, J. M., and Choudhury, B.: Determination of inundation area in the Amazon River floodplain using the SMMR $37 \mathrm{GHz}$ polarization difference, Remote Sens. Environ., 48, 70-76, 1994.
Sippel S. J., Hamilton, S. K., Melack, J. M., and Novo, E.: Passive microwave observations of inundation area and the area/stage relation in the Amazon River floodplain, Int. J. Remote Sens., 19, 3055-3074, 1998.

Ulaby, F. T., Moore, R. K., and Fung, A.: Microwave Remote Sensing: Active and Passive, Vol. III - Volume Scattering and Emission Theory, Advanced Systems and Applications, AddisonWesley, 1986.

Wang, Y., Hess, L., Filoso, S., and Melack, J.: Understanding the Radar Backscattering from Flooded and Nonflooded Amazonian Forests: Results from Canopy Backscatter Modeling, Remote Sens. Environ., 54, 324-332, 1995.

Zwenzner, H. and Voigt, S.: Improved estimation of flood parameters by combining space based SAR data with very high resolution digital elevation data, Hydrol. Earth Syst. Sci., 13, 567-576, doi:10.5194/hess-13-567-2009, 2009. 